\title{
SABERES EM MOVIMENTO NO ESTÁGIO DE REGÊNCIA DE TURMA: O ENSINO DE ANÁLISE LINGUÍSTICA POR GRADUANDOS DE LETRAS
}

\author{
LIVIA SUASSUNA (UFPE) ${ }^{1}$ \\ http://orcid.org/0000-0001-7422-2923 \\ SABRINA LEITE FÉLIX (UFPE) $)^{2}$ \\ http://orcid.org/0000-0001-5822-2544
}

\begin{abstract}
RESUMO: Neste estudo pretendemos analisar o modo como alunos da licenciatura em LetrasPortuguês da Universidade Federal de Pernambuco, durante o estágio curricular, atuam para ensinar seus alunos a refletir sobre a língua, concretizando um dos eixos de ensino desse componente curricular que é a análise linguística. A pesquisa, do tipo qualitativo-descritiva, teve como corpus projetos e relatórios de estágio, além de depoimentos dos estagiários, captados no seminário de encerramento das atividades de regência de turma do ensino fundamental. Para montar o referencial teórico, buscamos autores que tratam da formação docente, do estágio e do ensino de análise linguística. Os resultados mostraram que os futuros professores trabalham numa perspectiva sociointeracionista e exploram uma diversidade de gêneros textuais, como indicado nas orientações mais recentes para o ensino de língua portuguesa. No entanto, a maioria deles explicita pouco os procedimentos didáticos realizados, não indica as dificuldades dos alunos quando da avaliação da aprendizagem e aborda determinados conhecimentos linguísticos de forma expositiva e dedutiva.
\end{abstract}

PALAVRAS-CHAVE: Licenciatura. Estágio. Letras. Ensino de análise linguística.

\section{LINGUISTIC ANALYSIS TEACHING BY LETTERS UNDERGRADUATES}

\begin{abstract}
This study results from a broader research, which has the objective of analyzing and discussing different practices of supervised internship in the undergraduate course in LettersPortuguese at UFPE. In the subproject presented here, we intend to analyze the ways in which the licensee, during the class conducting internship, acts to teach his students to reflect on the language. We carried out a qualitative-descriptive research. The corpus consisted of internship projects and reports, in addition to oral testimonies from the interns, captured in the closing seminar of the Supervised Curricular Internship Course in Portuguese (elementary school class). For the theoretical framework, we use authors who deal with teacher training, internship and teaching linguistic analysis. The results showed that future teachers work in a socio-interactionist perspective and explore a diversity of textual genres. However, they do not make the teaching procedures performed explicit, they do not indicate the students' difficulties when assessing learning and they approach certain contents in an expositive and deductive way.
\end{abstract}

KEYWORDS: Teacher training. Internship. Linguistic analysis teaching.

\footnotetext{
1 Doutora em Linguística pela UNICAMP. Docente do Centro de Educação - Departamento de Métodos e Técnicas de Ensino e Programa de Pós-graduação em Educação da Universidade Federal de Pernambuco. Email: liviasuassuna60@gmail.com

${ }^{2}$ Licenciada em Letras - Português pela UFPE. Mestranda do Programa de Pós-graduação em Educação da UFPE. Ex-bolsista do Programa de Iniciação Científica da Fundação de Amparo à Ciência e Tecnologia do Estado de Pernambuco (FACEPE). E-mail: sabrinaleitefelix@gmail.com 


\section{$=$ TRAMA $=$}

\section{INTRODUÇÃO}

Este estudo resultou de uma pesquisa mais ampla, iniciada em 2014 e ainda em vigor, que objetiva, de forma ampla, investigar o papel do estágio curricular do curso de licenciatura em Letras-Português da UFPE na formação do futuro professor. No primeiro ano da pesquisa, investigamos, em dois subprojetos distintos: a forma como o estágio curricular estava disposto nas matrizes curriculares do curso, sendo uma recém-implantada na época, e a outra, em processo de extinção, procurando verificar se as mudanças implementadas reconfiguraram o estágio na perspectiva de uma formação mais processual do professor de português (subprojeto 1); e as representações dos alunos egressos de ambas as matrizes acerca da relação teoria-prática, objetivando saber deles em que medida a teoria e a prática foram articuladas durante o curso de graduação e se eles conseguiram desenvolver a "competência aplicada", entendida por Almeida Filho (2000) como a capacidade de viver profissionalmente o que se sabe teoricamente (subprojeto 2).

No ano de 2015, nos debruçamos sobre os modos como os estagiários atribuem sentidos às experiências vividas nos estágios curriculares de observação e regência de classe, buscando perceber se havia diferenças nesses processos interpretativos conforme o lugar a partir do qual o graduando faz a leitura da prática - como observador (subprojeto 1) ou como docente (subprojeto 2) - e as implicações disso para a formação profissional.

Os resultados de 2015 nos colocaram uma nova questão para investigar: tanto relatando a prática de outro professor, quanto relatando a própria prática, os licenciandos pareceram secundarizar as especificidades do conhecimento da área de referência (relativos à língua portuguesa e suas literaturas), priorizando questões mais globais do processo ensinoaprendizagem, tais como a valorização do conhecimento prévio dos alunos e a importância de atender às suas necessidades e interesses imediatos, as formas de enfrentamento das precárias condições materiais de trabalho nas escolas, aspectos identitários da profissão, entre outros. Mesmo sem negar a complexidade do trabalho docente nem a importância de atentar para as suas múltiplas dimensões no processo de formação de professores, julgamos que os chamados saberes disciplinares têm um lugar central quando se trata de aprender a ensinar algo, não podendo ser minimizados em nome da prática (OLIVEIRA, 2006).

Foi assim que, nos anos de 2016 e 2017, investigamos as relações dos licenciandos com os diversos saberes constitutivos de sua formação e atuação profissional, em particular aqueles chamados de disciplinares (mais diretamente relacionados ao campo epistemológico). Pesquisamos, então, por meio de projetos e relatos de estágio, como o professor em formação mobilizava saberes acerca da escrita (2016 - subprojeto 1), da leitura (2016 - subprojeto 2), da oralidade (2017 - subprojeto 1) e da análise linguística (2017 - subprojeto 2) para torná-las objetos de ensino-aprendizagem em sala de aula.

O objetivo específico do recorte aqui apresentado foi identificar e analisar os modos como o licenciando de Letras-Português, no estágio de regência de turma, atua para ensinar seus alunos a refletir sobre a língua, concretizando um dos eixos de ensino de português que é a análise linguística. Nossa pesquisa foi motivada por afirmações presentes em alguns estudos panorâmicos a respeito do tema: (a) há uma fluidez terminológica e de sentido em torno da análise linguística, que é tomada, inclusive, como procedimento metodológico; (b) a análise linguística tem sido muito menos explorada na sala de aula do que a leitura e a produção de textos; (c) não estão ainda bem claras as relações e as distinções entre análise linguística e gramática, o que vem implicando o abandono do estudo da estrutura da língua na educação 


\section{$=$ TRAMA $=$}

básica; (d) o ensino de análise linguística constitui um dos grandes desafios postos aos professores de português e seus formadores. ${ }^{3}$

\section{O ESTÁGIO NA LICENCIATURA: MOMENTO DE SÍNTESE DE VÁRIOS SABERES}

Os estudos mais recentes sobre a relação teoria-prática e o papel do estágio na licenciatura têm mostrado que se deve superar o chamado modelo prescritivista da racionalidade técnica, de cunho aplicacionista, pois este se baseia na crença de que os conhecimentos disciplinares, organizados hierarquicamente e acrescidos de matérias pedagógicas, culminariam, após o estágio, em práticas escolares bem-sucedidas. Essa tendência teórica se fortaleceu no Brasil especialmente nos anos 1990 e passou a constituir um discurso crítico do antigo modelo de licenciatura, no qual havia um alto investimento nos conteúdos da área de referência durante os três primeiros anos e a formação pedagógica se dava ao final da graduação, correspondendo ao que seria a "parte prática" do curso (modelo conhecido como $3+1)$.

Referência nesse debate é a proposição de Tardif, Lessard e Lahaye (1991). Os autores, reconhecendo a pluralidade dos saberes docentes, classificam-nos em quatro grandes tipos: a) saberes da formação profissional - dizem respeito aos saberes transmitidos pelas instituições diretamente responsáveis pela preparação profissional dos professores e às doutrinas ou concepções sobre a prática educativa, em termos de paradigmas teóricos; b) saberes disciplinares - produzidos socialmente por agentes e instituições de natureza científica, são relativos às diversas áreas do conhecimento e configurados em disciplinas como matemática, português, física, química etc.; c) saberes curriculares - compõem os programas curriculares e os livros didáticos; correspondem àquilo que as escolas e órgãos gestores/atores da educação em geral definem como essencial para se aprender e funcionam como orientadores do planejamento, da execução e da avaliação das atividades de sala de aula; d) saberes da experiência - são os saberes práticos, a partir dos quais os docentes interpretam e orientam seu fazer cotidiano; produzidos em contextos que requerem decisões mais imediatas, complexas e diversificadas, estão em permanente reelaboração e têm caráter sincrético.

Uma categorização como essa, entre outras proposições, se fez importante por levar a reconhecer que os docentes, na prática pedagógica, produzem e reelaboram saberes; refletem criticamente sobre eles; retraduzem sua formação quando atuam profissionalmente, reconstruindo de modo permanente sua identidade de professores; não são, portanto, meros transmissores de conhecimentos ou aplicadores de métodos de ensino.

Na esteira desse debate, o estágio curricular foi reconceptualizado, passando a ser visto como um momento privilegiado de síntese dos vários saberes necessários à ação docente, que pode propiciar ao licenciando oportunidades de vivência da relação teoria-prática. Enquanto atividade teórico-prática, o estágio permite ao licenciando conhecer, analisar e refletir sobre impasses e dificuldades do ensino-aprendizagem, como também pensar alternativas de reconstrução das práticas didáticas e pedagógicas, para o que são fundamentais os múltiplos saberes da formação.

Outro estudo de referência no campo é o de Pimenta e Lima (2006). As autoras entendem o estágio, para além de uma atividade prática instrumental, como campo de conhecimento. Nesse sentido, é fundamental auxiliar o estagiário a desenvolver uma atitude investigativa, de reflexão e de ação na vida da escola, sem perder de vista o significado social, cultural e humano da ação do professor. Para tanto, impõe-se que o conjunto dos saberes

${ }^{3}$ Cf. Reinaldo (2012), Vieira (2017), Dutra e Loula (2017), Callian e Botelho (2014), Dickel (2012), Remenche e Rohling (2017), entre outros.

Revista Trama | Volume 17 | Número 41 | Ano 2021 | p. 9-27 | e-ISSN 1981-4674 


\section{$=$ TRAMA $=$}

trabalhados ao longo da formação favoreça a análise, a crítica e a proposição de maneiras renovadas de fazer educação.

Buscando traçar uma concepção ampla de estágio, Pimenta e Lima o entendem como aproximação da realidade da escola, e não como a parte estritamente prática do curso. Assim, a formação converge para a capacidade de compreender/problematizar as situações observadas/vividas, buscando estabelecer relações entre as teorias existentes e os dados novos/singulares da realidade, percebidos a partir da postura investigativa. Nesse caso, as teorias têm um grande poder formativo, não por serem verdades absolutas, transplantáveis para um contexto específico, mas porque dotam o docente em formação de pontos de vista variados sobre a ação contextualizada. Dizem as autoras:

o papel da teoria é oferecer aos professores perspectivas de análise para compreenderem os contextos históricos, sociais, culturais, organizacionais e de si mesmos como profissionais, nos quais se dá sua atividade docente, para neles intervir, transformando-os. Daí, é fundamental o permanente exercício da crítica das condições materiais nas quais o ensino ocorre (PIMENTA; LIMA, 2006, p. 16).

Tal perspectiva aponta para a formação dos docentes como intelectuais críticos e reflexivos, e para o estágio como parte integrante do corpo de conhecimentos dos cursos de licenciatura. Caberia, pois, ao estágio

desenvolver atividades que possibilitem o conhecimento, a análise, a reflexão do trabalho docente, das ações docentes nas instituições, de modo a compreendêlas em sua historicidade, identificar seus resultados, os impasses que apresenta, as dificuldades. Dessa análise crítica, à luz dos saberes disciplinares, é possível apontar as transformações necessárias no trabalho docente nas instituições (PIMENTA; LIMA, 2006, p. 20).

Esse conhecimento envolve, de acordo com Pimenta e Lima:

o estudo, a análise, a problematização, a reflexão e a proposição de soluções às situações de ensinar e aprender. Envolve também experimentar situações de ensinar, aprender a elaborar, executar e avaliar projetos de ensino não apenas nas salas de aula, mas também nos diferentes espaços da escola. Por isso, é importante desenvolver nos alunos, futuros professores, habilidades para o conhecimento e a análise das escolas, espaço institucional onde ocorre o ensino e a aprendizagem, bem como das comunidades onde se insere. Envolve, também, o conhecimento, a utilização e a avaliação de técnicas, métodos e estratégias de ensinar em situações diversas. Envolve a habilidade de leitura e reconhecimento das teorias presentes nas práticas pedagógicas das instituições escolares (PIMENTA; LIMA, 2006, p. 20-21).

Somamos ao ponto de vista de Pimenta e Lima (2006) um estudo de Siqueira e Messias (2008), no qual as autoras se valem do conceito de experiência tal como proposto por Jorge Larrosa (2004): como modo de habitar o mundo, como o vivido que nos interpela, que ressoa em nós; como paixão, da qual se desprende uma epistemologia, uma ética, uma política e uma pedagogia. Desse ponto de partida, Siqueira e Messias atribuem legitimidade à experiência no campo pedagógico, o que implica receptividade, abertura e disponibilidade, essenciais ao diálogo.

A assunção da experiência como conceito vital da pedagogia conduz à questão da reflexão e da autoria. Assim, Siqueira e Messias (2008) julgam que a constituição do professor como autor de sua própria prática requer a elaboração de sínteses de pressupostos teóricos e mecanismos de conduta das atividades de ensino-aprendizagem em sala de aula. E a autoria 


\section{$=$ TRAMA $=$}

assim concebida também deveria constituir os projetos educativos de formação de professores, "em consonância com os valores e a estrutura social na qual essa formação profissional se institui”" (SIQUEIRA; MESSIAS, 2008, p. 381).

\section{PERSPECTIVA SOCIOINTERACIONISTA DE LINGUAGEM E FORMAÇÃO DO PROFESSOR DE PORTUGUÊS}

Nas últimas décadas, vem-se consolidando um modelo metodológico de ensino baseado na noção de língua como interação, conceito que colocou o texto no centro do trabalho didático-pedagógico, pois é através do texto, e não de palavras e frases, que efetivamos nossas interações verbais. Em torno do texto, em suas diferentes configurações, devem ser desenvolvidas práticas de leitura, escrita, oralidade e análise linguística, de forma a expandir a experiência interlocutiva dos aprendizes, tendo em vista a variabilidade de usos da língua em contextos sócio-históricos definidos.

Tal perspectiva requer uma abordagem sistemática das diferentes práticas de linguagem de modo a que os alunos ampliem seus conhecimentos sobre a língua, na mesma medida em que a praticam, conforme postula Azevedo (2010). Essa autora sustenta que a aula de português tenha como objetivo central "fazer aprender a usar essa língua como meio de interlocução, quer no que se refere à recepção (oral e/ou escrita), quer no que diz respeito à produção (novamente, oral e/ou escrita)" (AZEVEDO, 2010, p. 200). Em outras palavras, ensinar língua materna significa "expor o sujeito aprendiz a diferentes situações de emprego da língua, seja na modalidade escrita para aprendê-la, seja na modalidade oral para aperfeiçoá-la" (idem, p. 209).

Num outro trabalho além do já mencionado, Azevedo (2014) afirma que ler e escrever são habilidades e, nessa condição, pressupõem ação por parte dos aprendizes. Trata-se de um saber fazer, um saber operacional; por isso, transmitir ao aluno informações relativas à configuração morfossintática, fonológica e mesmo textual da língua pouco contribui para o desenvolvimento dessas habilidades. Nas palavras da autora: "pouco adianta para os alunos que os docentes falem sobre a língua, suas classes gramaticais, as funções sintáticas dos termos que a compõem ou o 'desenho' estrutural de cada gênero textual” (AZEVEDO, 2014, p. 93, grifos da autora). O que realmente vale na aula de português é "compreender e produzir a intrincada teia de inter-relações sintático-semânticas que constituem o todo sistemicamente organizado que é o discurso como unidade de sentido" (idem, p. 102).

Ainda conforme Azevedo (2014), uma prática consistente de ensino de português estaria assentada em três princípios: (1) o estudo de uma língua se faz por meio da própria língua; (2) a teoria, no que tange ao ensinar/aprender uma língua, não é representada pela gramática normativa ou pela metalinguagem, mas pela reflexão referente ao uso dessa língua; trata-se de tomar consciência de diversos modos de realização do sistema linguístico e não de ouvir falar sobre ele e nomear seus constituintes; e (3) não há desenvolvimento de habilidades sem a ação a ele inerente, ou seja, para aprender a usar uma língua, é necessário falar, ouvir/compreender, ler e escrever essa língua (ação/reflexão/ação).

Petroni, Justino e Melo (2011), referindo-se ao novo paradigma de ensino de língua, afirmam que esta demanda a formação de um professor capaz de promover em sala de aula o desenvolvimento de competências linguístico-discursivas adequadas a diferentes situações discursivas. Nesse sentido, a especificidade da aula de português, marcada pela intrínseca relação entre o uso da língua e sua análise, alia-se às especificidades da formação do professor de português, responsável pela transformação do conhecimento empírico da língua que o aluno traz consigo em conhecimento do funcionamento da língua. 


\title{
$=$ TRAMA $=$
}

Lombardi e Arbolea (2006, p. 1), por sua vez, afirmam:

\begin{abstract}
falar do conhecimento teórico que deve ser apresentado ao aluno de Letras significa determinar o domínio de conhecimento do objeto linguagem que envolve um saber relativo à língua, enquanto fato linguístico, visto nas dimensões estrutural, semântica, histórica, interacional e discursiva.
\end{abstract}

$\mathrm{Na}$ visão das autoras, em paralelo aos estudos da linguagem, é preciso desenvolver conhecimentos relativos à educação em geral e ao ensino-aprendizagem em particular, para que o futuro professor possa experienciar o fazer didático-pedagógico, associando o conhecimento teórico à prática, pesquisando e tomando decisões.

Citamos aqui também um artigo de Rauber (2008) em que o autor defende que o conhecimento linguístico não tem de, necessariamente, ser transferido ou aplicado no ensino básico. Mas, de qualquer forma, esse saber "tem influência determinante sobre as opções, conscientes ou não, que serão feitas pelo futuro professor perante os fatos da língua e, consequentemente, de seu ensino em sala de aula" (p. 347). Após analisar questionários com que pretendeu verificar como alunos do $3^{\circ}$ e $4^{\circ}$ anos do curso de licenciatura em Letras da UFMT - campus Rondonópolis percebem a relação entre os conteúdos vistos durante a graduação e sua futura prática na aula de português do ensino fundamental e médio, Rauber (2008) constatou que há uma instabilidade manifesta na relação entre a aprendizagem de conteúdos substantivos da formação inicial em Letras e sua aplicação na educação básica.

Em matéria de formação do professor, portanto, é necessário dotá-lo de um conhecimento especializado sobre a língua que informe uma pedagogia que tome o texto/discurso, em suas várias facetas, como objeto privilegiado de ensino-aprendizagem. Dito de outro modo, não basta que o professor mande o aluno ler/escrever/falar/ouvir: há propriedades textuais a explorar, estratégias de produção de sentido a identificar, recursos expressivos a mobilizar quando dessas práticas de linguagem. Pode-se deduzir disso que os chamados saberes eruditos da área de referência, embora imprescindíveis, não são em absoluto suficientes para formar professor de português e qualificar o seu agir em sala de aula.

\section{O ENSINO DE ANÁLISE LINGUÍSTICA}

A expressão análise linguística vem sendo utilizada no Brasil desde meados dos anos 1980, quando, a partir da proposta pioneira de Geraldi (1984), delineou-se um ensino de português de base sociointeracionista. O termo foi proposto pelo autor para nomear uma das práticas estruturantes desse ensino - a reflexão sistemática sobre a linguagem -, no lugar do tradicional ensino de gramática normativa e em articulação com as práticas de leitura e produção de textos, em contextos significativos de interação.

Dickel (2012) pretendeu sistematizar algumas das principais contribuições de estudiosos do tema, partindo do princípio de que, na escola, os alunos devem encontrar condições para "aprender a considerar que a língua é um objeto que se pode manipular, sobre o qual se pode falar e sobre o qual é fundamental ter conhecimentos explícitos" (p. 1). Essa perspectiva requer "a ampliação dos limites estabelecidos pelo mundo cultural mais próximo e das possibilidades de uso da e de intervenção pela linguagem nos diversos contextos socioculturais dos quais esses sujeitos participam ou venham a participar" (p. 1).

A autora concluiu que as concepções de gramática e análise linguística se modificaram ao longo da história e se projetaram para os discursos, documentos e práticas curriculares, ainda em meio a muitas polêmicas e indefinições, sobretudo no campo da didática. Sustenta que, entre outras finalidades, a escola é um lugar apropriado "para o exercício da ação 
intencional sobre os processos psicológicos, dentre os quais [...] agir com e sobre a própria língua" (p. 19). Nessa direção, resta ainda esclarecer melhor "em que isso consiste, mediante que propostas se realiza e que efeitos produz sobre a formação e a atuação dos sujeitos" ( $p$. 19). E essa tarefa deve ser assumida solidariamente por estudiosos de diferentes áreas implicadas no processo ensino-aprendizagem da língua (ex.: psicologia, linguística, didática, metodologia).

O desafio de articular a análise linguística, enquanto prática de reflexão sobre a língua, com a leitura e a produção textual no trabalho de sala de aula foi apontado por Remenche e Rohling (2017), a despeito dos esforços empreendidos nos últimos trinta anos, seja na produção de estudos acerca do tema, seja em programas diversos de formação inicial e continuada de docentes. A análise linguística é entendida pelas autoras como uma das práticas de letramento escolar; nessa perspectiva, as atividades relativas a esse eixo de ensino "precisam ir além da exploração de aspectos de metalinguagem, explorando saberes linguísticos vinculados ao uso da linguagem e leitura/produção dos gêneros discursivos" (REMENCHE; ROHLING, 2017, p. 2705).

Para tanto, a formação de professores de português irá requerer o desenvolvimento de uma postura reflexiva, no sentido de que eles consigam desenvolver processos de ensinoaprendizagem que levem os estudantes a se apropriar não só de "conhecimentos declarativos e conceituais", como também de "procedimentos e saberes emancipatórios para que possam agir em diferentes situações sociais" (REMENCHE; ROHLING, 2017, p. 2706).

Para as autoras, é importante que a prática da análise linguística - que deve contemplar os diferentes níveis de funcionamento da língua - não seja vista de forma dicotômica em relação à leitura e à produção de textos orais e escritos:

\begin{abstract}
Esse pensar visa à compreensão do funcionamento interno da língua e precisa caminhar de uma percepção intuitiva dos fatos a uma progressiva reflexão consciente e sistematização, acompanhada da introdução do vocabulário gramatical básico, de modo a desenvolver uma atitude intencional de observar e descrever a organização da língua. Nessa dinâmica, esses sujeitos [os alunos] mobilizam estratégias de leitura e de escrita ao mesmo tempo em que refletem sobre questões relacionadas à análise da língua em um movimento de interdependência, não dicotomizando a reflexão sobre os conhecimentos linguísticos e os seus usos, pois refletir sobre os usos da linguagem implica refletir sobre os conhecimentos linguísticos com os quais interagimos nas diferentes situações sociais (REMENCHE; ROHLING, 2017, p. 2707-2708).
\end{abstract}

Na conclusão do estudo, Remenche e Rohling (2017), após analisarem discursos de licenciandos de um curso de Letras Português-Inglês de uma universidade pública do sul do Brasil, afirmam que, no contexto da formação inicial do professor de português, a descentração do papel da gramática está em curso, assim como ocorre com os processos de elaboração didática da análise linguística vivenciados por esses sujeitos em práticas de estágio. O enfrentamento do desafio inicialmente apontado exige, segundo elas, a substituição dos quadros teóricos próprios da tradição gramatical por práticas que envolvam os diferentes usos da língua. E nesse movimento têm grande responsabilidade as instituições formadoras dos futuros professores de português. 


\section{$=$ TRAMA $=$}

\section{METODOLOGIA}

Realizamos uma pesquisa qualitativo-descritiva, cujo corpus foi constituído por projetos e relatórios de estágio produzidos por alunos do Estágio Curricular Supervisionado em Português 3 (regência de turma de nível fundamental - anos finais) do curso de licenciatura em Letras-Português da UFPE, do ano letivo de 2016. Também nos valemos de relatos orais feitos por esses mesmos alunos no seminário de conclusão da disciplina.

A turma definida para a pesquisa tinha 25 alunos. Desse total, foram selecionados, aleatoriamente, cinco relatórios de estágio, cinco projetos didáticos e cinco relatos orais, correspondentes entre si, num total de 15 objetos de análise. Usamos o código PD para projeto didático, RE para relatório escrito e $\mathrm{RO}$ para relato oral, de modo que os projetos didáticos, relatórios e relatos orais selecionados foram assim identificados: RE1, RE2, RE3, RE4 e RE5 / PD1, PD2, PD3, PD4 e PD5 / RO1, RO2, RO3, RO4 e RO5. ${ }^{4}$

Escolhemos esse material porque entendemos que o estágio de regência é um momento que permite ao estagiário analisar e refletir sobre questões que dizem respeito ao processo de ensino-aprendizagem. Especificamente, analisamos como os professores em formação mobilizam saberes para, na perspectiva da análise linguística, ensinarem seus alunos a refletirem sobre a língua. Levamos em conta também a pertinência de tomar relatórios de estágio como material privilegiado de pesquisa nos campos da linguística e da educação, tal como demonstrado por Silva e Fajardo-Turbin (2011), na medida em que podem funcionar "como atividade de reflexão crítica sobre as práticas pedagógicas experienciadas por professores em formação inicial" (SILVA; FAJARDO-TURBIN, 2011, p. 103).

Quanto aos critérios de análise, foram estabelecidos com base nos princípios teóricos já indicados acerca do estágio, dos saberes docentes e da análise linguística, bem como da orientação metodológica sugerida atualmente para o ensino do português. Assim, empreendemos nossa análise consoante os critérios enumerados a seguir: (1) apropriação dos fundamentos que embasam o ensino da análise linguística no quadro do sociointeracionismo; (2) decisões sobre o que e para que ensinar, e como avaliar a aprendizagem da análise linguística; (3) síntese de saberes por parte do estagiário; (4) descrição do processo de didatização dos conteúdos.

\section{O QUE OS DADOS REVELAM SOBRE O ENSINO DE ANÁLISE LINGUÍSTICA POR LICENCIANDOS}

Procedemos à análise dos dados tendo em vista que as teorias que fundamentam a formação de professores não são aplicadas de modo direto, mas funcionam como base para um fazer docente que relaciona teoria e prática, e contribuem para a elaboração didática dos objetos de ensino na educação básica. Passemos aos resultados, organizados conforme os critérios anunciados.

\footnotetext{
${ }^{4} \mathrm{O}$ projeto didático elaborado pelos estagiários contém a contextualização e a caracterização da escola e da turma a ser regida, a fundamentação teórica, a justificativa da escolha da temática e dos conteúdos selecionados, além do detalhamento do plano das aulas. O relatório escrito corresponde ao relato, teorizado e com exemplificações, das experiências vivenciadas na escola e na sala de aula. O relato oral é feito nas duas últimas aulas de estágio, na forma de roda crítica, quando os estagiários apresentam e debatem suas vivências. Esses três tipos de trabalhos funcionam como instrumentos avaliativos do estágio e para todos eles são oferecidas orientações específicas de elaboração. 


\section{$=\mathrm{T} R A M A=$}

CRITÉRIO 1: APROPRIAÇÃO DOS FUNDAMENTOS QUE EMBASAM O ENSINO DA ANÁLISE LINGUÍSTICA NO QUADRO DO SOCIOINTERACIONISMO

Segundo Geraldi (1997[1984]), a língua só tem existência na interlocução, portanto, na visão sociointeracionista, o ensino-aprendizagem será pautado na linguagem como uma prática social e discursiva e situada num determinado contexto sócio-histórico. Isso "implicará uma postura educacional diferenciada, uma vez que situa a linguagem como o lugar de constituição de relações sociais, onde os falantes se tornam sujeitos" (GERALDI, 1997, p. 2-3). Consequentemente, o ensino de análise linguística irá partir de situações concretas de uso da língua e seu foco se desloca da classificação e da memorização de elementos e regras gramaticais para os processos de produção de sentido. A reflexão sobre a língua visa a levar os alunos a pensar sobre os fenômenos linguístico-gramaticais e construir conhecimentos sobre eles.

Em relação ao critério 1, todos os projetos didáticos, relatórios de estágio e relatos orais demonstram que os estagiários têm conhecimento do sociointeracionismo e reconhecem sua importância para o desenvolvimento do ensino da análise linguística. Nos cinco PD analisados, os princípios do sociointeracionismo aparecem na fundamentação teórica utilizada, no estabelecimento dos conteúdos e metas de aprendizagem, e na descrição dos procedimentos didáticos. Nos RE, pudemos notar que os estagiários buscaram desenvolver as atividades de análise linguística com base no texto:

RE1

Pudemos fazer a leitura do texto para discutir o tema e a partir do texto ligar e explicitar a funcionalidade dos modos verbais no texto e destacar seu papel na construção do conto.

\section{RE}

De início, fiz a análise da tirinha de Orlandeli, a fim de explicar o comportamento semântico e sintático do verbo 'passar'.

\section{RE3}

O segundo eixo a ser trabalhado foi o da análise linguística, os conteúdos abordados foram concordância verbal e nominal e refletimos com os alunos sobre a importância desses elementos gramaticais na construção do texto.

\section{RE4}

Utilizando os textos lidos na sala de aula e a produção textual dos alunos, iniciei o trabalho de análise linguística.

\section{RE5}

No tratamento do eixo da análise linguística, investigamos o efeito que recursos gramaticais causam na estruturação do elemento catártico no texto literário.

A análise de nossa amostra permitiu concluir que há um conhecimento da proposta sociointeracionista de ensino de análise linguística por parte dos estagiários: os conteúdos escolhidos como objetos de ensino são prioritariamente os gêneros textuais e a reflexão sobre a língua foi realizada dentro dos exemplares dos textos estudados. 


\section{$=\mathrm{T} R A M A=$}

\section{CRITÉRIO 2: DECISÕES SOBRE O QUE E PARA QUE ENSINAR, E COMO AVALIAR A APRENDIZAGEM}

\section{CONTEÚDO DA AULA DE ANÁLISE LINGUÍSTICA}

Callian e Botelho (2014) dizem que um dos maiores problemas do ensino da gramática na sala de aula é a redução da língua à norma culta: "as escolas consolidaram o uso de uma gramática equivocada, que reduz a língua, não oferecendo uma compreensão mais ampla, mais relevante, do que sejam os usos da linguagem" (p. 4). Em contraposição a isso, as orientações para o ensino da língua descritas em nosso referencial teórico sugerem que a análise linguística perpasse as práticas de linguagem "tendo por objetivo desenvolver nos alunos as habilidades de leitura, de escuta e de produção de textos escritos e orais, além da capacidade de interpretação e produção de sentidos enquanto eles realizam essas práticas" (NÓBREGA e SUASSUNA, 2014, p. 251). Em relação aos conteúdos de análise linguística, todos os sujeitos analisados demonstraram reconhecer a importância de definir os objetos de ensino no contexto de práticas de linguagem efetivas, usando diferentes gêneros textuais para o desenvolvimento das aulas, conforme mostrado a seguir.

\begin{tabular}{|c|c|c|c|c|}
\hline $\begin{array}{c}\text { Conteúdos } \\
\text { PD1 }\end{array}$ & $\begin{array}{c}\text { Conteúdos } \\
\text { PD2 }\end{array}$ & $\begin{array}{c}\text { Conteúdos } \\
\text { PD3 }\end{array}$ & $\begin{array}{c}\text { Conteúdos } \\
\text { PD4 }\end{array}$ & $\begin{array}{c}\text { Conteúdos } \\
\text { PD5 }\end{array}$ \\
\hline Conto & Tirinha & $\begin{array}{c}\text { Conto e artigo de } \\
\text { opinião }\end{array}$ & Artigo de opinião & $\begin{array}{c}\text { Artigo de opinião } \\
\text { e poema }\end{array}$ \\
\hline
\end{tabular}

Em termos da delimitação de conteúdos gramaticais específicos, observamos que, em três casos (RE1, RE2 e RO4), os estagiários, embora pudessem ter escolhido os gêneros textuais com que trabalhar, no sentido de desenvolver em seus alunos a capacidade de reflexão sobre os fenômenos linguísticos, tiveram que se adaptar a conteúdos exigidos pelos professores supervisores:

\section{RE1}

Para começar a desenvolver o eixo da análise linguística tive que utilizar, por pedido do professor supervisor, conteúdos que seriam abordados na prova da unidade. Os assuntos selecionados pelo professor para complementar suas atividades foram: tempo e espaço na narrativa, e explorar resumidamente o assunto de modos verbais.

\section{RE2}

O eixo de análise linguística foi baseado no currículo da escola, por isso, precisei adequar o assunto de predicação verbal ao gênero tirinha.

\section{$\mathrm{RO} 4$}

O tema do projeto e o conteúdo de análise linguística foi a professora que pediu que eu fizesse esse assunto que estava no livro, e era sobre o idoso, o conteúdo gramatical que ela ia fazer a prova da última unidade era processo de formação de palavras.

Em RE/RO 3 e 5, verificou-se que os sujeitos definiram os conteúdos gramaticais de forma mais livre, em conformidade com seus planejamentos: 


\section{$=$ TRAMA $=$}

RE3

O segundo eixo a ser trabalhado foi o da análise linguística e os conteúdos abordados foram concordância verbal e nominal e refletimos com os alunos sobre a importância desses elementos gramaticais na construção do texto.

$\mathrm{RO} 3$

Fomos trabalhar com concordância verbal e nominal e tentar tirar exemplos dos textos.

\section{RE5}

No tratamento do eixo da análise linguística, investigamos o efeito que alguns recursos gramaticais causavam na estruturação do elemento catártico no texto literário.

Seja escolhendo os conteúdos mais livremente, seja trabalhando com o que foi determinado pelo professor supervisor, vimos que os estagiários buscaram relacionar os assuntos tratados às especificidades dos gêneros textuais ou conferir-lhes um caráter mais discursivo ou fazer os alunos reconhecerem o papel dos elementos gramaticais na construção do texto. No segundo caso - determinação prévia do conteúdo -, eles tiveram uma certa dificuldade para realizar um ensino diferenciado e mais produtivo, incorrendo, algumas vezes, em práticas tradicionais de nomeação e classificação. Por exemplo, o sujeito 4 teve dificuldade de relacionar o conteúdo linguístico que o professor supervisor havia determinado (formação de palavras) com o gênero textual artigo de opinião:

\section{$\mathrm{RO} 4$}

O pior da regência foi o conteúdo de análise linguística, pior no sentido de planejar para ensinar, é difícil porque você começa retirando palavras do texto pra exemplificar o processo de formação de palavras, você sempre tende a ir para o tradicional, quer classificar, nomear.

Sobre essa dificuldade revelada no RO4, lembramos Barbosa (2010), que propõe que a aula de análise linguística se dê de forma inversa ao que é costumeiro: "Trata-se de selecionar conteúdos a partir das necessidades apresentadas pelos alunos nas atividades de produção e compreensão de textos" (p. 158).

\section{FINALIDADES DO ENSINO DE ANÁLISE LINGUÍSTICA}

Como dito, a análise linguística deve ter como foco a significação e a função dos elementos constitutivos da língua dentro do texto. Assim, as metas de aprendizagem para o desenvolvimento da análise linguística devem privilegiar "uma reflexão sobre a funcionalidade das escolhas que o falante faz e sobre os resultados de sentido que cada escolha desencadeia." (EMILIO, 2007, p. 35). Além disso, o desenvolvimento da reflexão sobre a língua deve se dar no contato com diversas variedades da língua, para desenvolver o senso de adequação linguística aos contextos de uso.

Analisando as metas de aprendizagem elencadas nos projetos didáticos, constatamos que os estagiários tanto contemplaram as capacidades de identificar e classificar unidades e estruturas, e de empregar regras da norma culta, como procuraram levar os aprendizes a refletir sobre os processos de construção dos sentidos dos diversos textos, com predominância do primeiro tipo.

Em três projetos (PD1, PD3 e PD4) revela-se certa dificuldade para o traçado de metas de aprendizagem que contribuam para o desenvolvimento de um senso crítico acerca dos usos linguísticos. As metas praticamente se limitam à identificação e utilização de regras e à classificação. Além disso, no PD1, há uma meta que evidencia a identificação de estruturas 


\section{$=\mathrm{TRAMA}=$}

certas e erradas de forma absoluta, quando as novas proposições metodológicas sugerem promover uma reflexão acerca da língua que ajude os alunos a entender a adequação linguística ao contexto de uso:

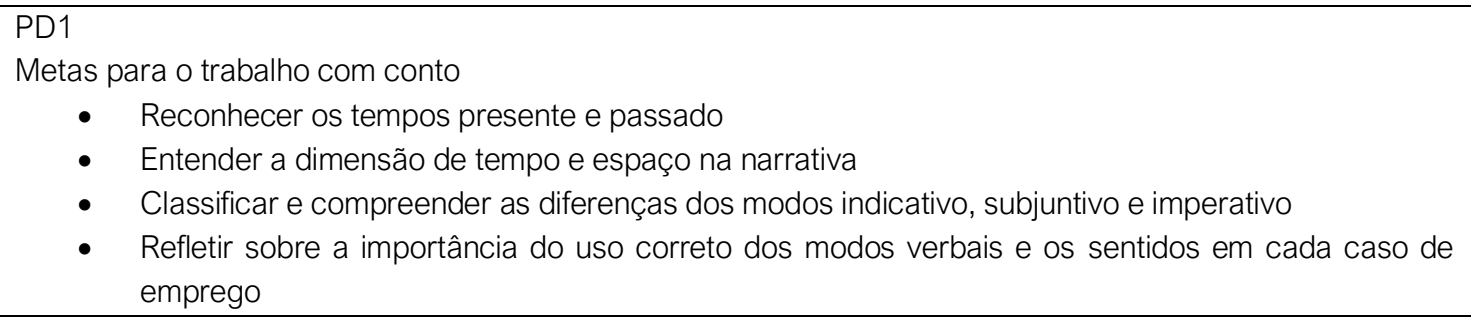

PD3

Metas para o trabalho com conto e artigo de opinião

- Compreender as características do gênero artigo de opinião

- Empregar regras de concordância nominal e verbal na produção de gêneros escritos da esfera pública

- Reconhecer relações de concordância entre o verbo e o sujeito de uma oração, refletindo sobre o funcionamento sintático da língua

\section{PD4}

Metas para o trabalho com artigo de opinião

- Identificar os processos de formação de palavras

- Reconhecer como as palavras funcionam no texto estabelecendo ou modificando sentidos

- Identificar o valor semântico que uma palavra pode apresentar dependendo do contexto de uso

O PD2 apresentou metas de aprendizagem que evidenciam uma maior reflexão acerca dos elementos linguísticos, o que pode contribuir para propiciar uma melhor compreensão do gênero textual tirinha; além disso, houve também a preocupação de discutir assuntos mais atuais e diversificados, como variação linguística, adequação da linguagem aos contextos de uso, linguagem verbal e não verbal, elementos linguísticos próprios do gênero tirinha:

PD2

Metas para o trabalho com tirinha

- Compreender a relação existente entre a sintaxe e a semântica do verbo

- Perceber como os elementos estruturais do gênero tirinha, os recursos linguísticos, paralinguísticos e organizacionais, além dos recursos visuais e de expressividade se manifestam na tirinha

- Relacionar linguagem verbal e não verbal para compreender o sentido da tirinha

- Expor as conclusões a partir das análises das tiras

- Entender como fatores sociais, econômicos e regionais podem interferir na linguagem dos personagens.

- Compreender como se dá a adequação/inadequação da linguagem de acordo com o contexto de uso

- Registrar conclusões sobre os personagens e suas linguagens

O PD5 apresenta uma meta de aprendizagem que associa a análise linguística à prática de produção textual (aspecto positivo, pois a reflexão sobre a língua deve perpassar todas as práticas de linguagem), além de trazer a relação entre estrutura linguística e literariedade: 


\section{$=\mathrm{T} R A M A=$}

- Utilizar elementos modalizadores e introdutores de opinião na produção de sequências argumentativas na estrutura linguística do artigo de opinião

- Associar elementos literários a aspectos estruturais

- Entender o papel da gramática no texto literário.

- Identificar jogos sintáticos que se destaquem na poética da autora e analisar o modo como tais ferramentas se articulam nos poemas

\section{AVALIAÇÃO DA APRENDIZAGEM DA ANÁLISE LINGUÍSTICA}

No que diz respeito à avaliação, Mendonça (2007, p. 103) afirma: "a avaliação da prática de $\mathrm{AL}$ deve considerar a construção de competências e habilidades de linguagem, $\mathrm{O}$ que não pode ser atingido por meio de avaliações pontuais, que enfoquem apenas ou principalmente aspectos estruturais e normativos". Nessa perspectiva, os instrumentos avaliativos precisam ser variados e mobilizar os conhecimentos construídos pelos alunos, e os critérios devem ser consistentes e devidamente relacionados às metas de aprendizagem anteriormente traçadas.

Em termos da avaliação da aprendizagem da análise linguística, os cinco projetos didáticos apresentam instrumentos e critérios avaliativos; no entanto, nos relatórios de estágio e nos relatos orais, não aparece menção específica à avaliação da aprendizagem. Apresentamos abaixo a forma como o item avaliação aparece em cada projeto.

\begin{tabular}{|l|l|}
\hline \multicolumn{2}{|c|}{ PD1 } \\
\hline INSTRUMENTOS & CRITÉRIOS \\
\hline - Participação oral & Verificar se os alunos conseguiram \\
- Produção escrita na ficha & $\bullet$ internalizar o conceito de espaço, tempo e extensão \\
- Ler a produção dos alunos e corrigi-las & - associar o assunto ao seu dia a dia \\
em conjunto & - compreender os diferentes gêneros textuais \\
& - entender cada modo verbal \\
& - identificar os modos verbais no texto \\
\hline
\end{tabular}

\begin{tabular}{|c|c|}
\hline \multicolumn{2}{|c|}{ PD2 } \\
\hline INSTRUMENTOS & CRITÉRIOS \\
\hline $\begin{array}{l}\text { - Trabalho em grupo } \\
\text { - Exposição oral } \\
\text { - Pesquisa } \\
\text { - Registro de análise }\end{array}$ & $\begin{array}{l}\text { - } \text { Compreensão da relação entre a sintaxe e a semântica } \\
\text { - } \text { do verbo } \\
\text { - } \text { Relação entre linguagem verbal e não verbal } \\
\text { - Capacidade de expor as conclusões a partir de análises } \\
\text { - Capacidade de pesquisa } \\
\text { - Compreensão da influência que fatores sociais, } \\
\text { - } \quad \text { econômicos e regionais têm na linguagem } \\
\text { - } \text { de uso }\end{array}$ \\
\hline \multicolumn{2}{|r|}{ PD3 } \\
\hline INSTRUMENTOS & CRITÉRIOS \\
\hline $\begin{array}{l}\text { - Fichas de exercícios } \\
\text { - Questionamentos orais } \\
\text { - Atividade impressa } \\
\text { - Síntese do conteúdo sobre } \\
\text { concordância nominal e verbal }\end{array}$ & $\begin{array}{l}\text { Verificar se os alunos } \\
\text { - } \quad \text { compreendem as características do gênero estudado } \\
\text { - } \text { compreendem o que são recursos de coesão textual } \\
\text { - } \text { sabem reconhecer os elementos conectores } \\
\text { - } \text { entendem a importância das conjunções para a coesão } \\
\text { textual } \\
\text { - empregam corretamente as regras de concordância } \\
\text { nominal }\end{array}$ \\
\hline
\end{tabular}




\section{$=\mathrm{T} R A M A=$}

\begin{tabular}{|l|l|}
\hline$\bullet$ & $\begin{array}{l}\text { reconhecem as relações de concordância entre o verbo e } \\
\text { o sujeito de uma oração } \\
\text { empregam corretamente as regras de concordância } \\
\text { verbal }\end{array}$ \\
\hline
\end{tabular}

\begin{tabular}{|l|l|}
\hline \multicolumn{2}{|c|}{ PD4 } \\
\hline INSTRUMENTOS & CRITÉRIOS \\
\hline - Atividade de reflexão sobre as palavras & $\begin{array}{l}\text { Verificar se os alunos conseguem } \\
\text { - reconhecer como acontece o processo de formação de } \\
\text { palavras e como elas funcionam dentro do texto } \\
\text { perceber como as palavras estabelecem ou modificam } \\
\text { sentidos dentro do texto }\end{array}$ \\
\hline
\end{tabular}

\begin{tabular}{|l|l|}
\hline \multicolumn{2}{|c|}{ PD5 } \\
\hline INSTRUMENTOS & CRITÉRIOS \\
\hline $\begin{array}{l}\text { - Atividade de análise dos verbos } \\
\text { modalizadores }\end{array}$ & - Perceber a capacidade dos alunos de identificar e aplicar \\
- Debate a respeito do poema lido & de modo coerente expressões modalizadoras \\
- Anotações na folha da cópia do poema & Checar o entusiasmo na análise do poema; conferir se \\
- Exercícios de interpretação textual & há ainda alunos passivos \\
voltados para hibridismos no texto & - Averiguar a capacidade ética e estética do aluno \\
\hline
\end{tabular}

Nossa análise evidenciou que os estagiários definiram estratégias e instrumentos variados de avaliação, entre eles: participação em discussões orais; produção escrita em fichas didáticas; correção coletiva de textos e atividades; registro escrito de conclusões; pesquisa; síntese coletiva dos conhecimentos; debate; exercício escrito de interpretação textual. Entretanto, indo de encontro ao que propõe Mendonça (2007), os licenciandos, ao traçar os critérios de avaliação, privilegiaram as competências e habilidades de reconhecimento e compreensão, em prejuízo de capacidades de uso da língua em contextos variados. Nos casos em que o uso foi contemplado, as competências e habilidades diziam respeito ao emprego correto de regras de concordância nominal e verbal, sem contemplar o viés textual-discursivo.

\section{CRITÉRIO 3: SÍNTESE DE SABERES POR PARTE DO ESTAGIÁRIO}

Por meio do critério 3, pretendíamos verificar como o estagiário agencia saberes para promover a aprendizagem dos seus alunos. No caso dos saberes disciplinares, buscamos perceber se os conhecimentos linguísticos iam além do que consta nas gramáticas tradicionais e incluíam aspectos textuais e discursivos. No caso do saber didático-pedagógico, atentamos para a construção de situações significativas de uso da língua (leitura, escrita e oralidade) que pudessem facilitar a reflexão, a compreensão e a construção do conhecimento metalinguístico. Só identificamos um relatório em que a estagiária, além de explorar um fenômeno gramatical de modo mais ampliado, o fez mobilizando os saberes prévios dos alunos, vinculando a reflexão sobre a língua a uma situação de compreensão e interpretação de textos (no caso, tirinhas) e estimulando a construção de hipóteses acerca da língua, como demonstrado abaixo.

\section{RE2}

O eixo de análise linguística foi baseado no currículo da escola, por isso, precisei adequar o assunto de predicação verbal ao gênero tirinha. Sabendo do conhecimento prévio deles sobre predicação verbal (trabalhado pela professora supervisora durante meu período de observação), perguntei se eles saberiam dizer a predicação do verbo 'passar' na tira. Prontamente, falaram que era intransitivo, pois não tinha um objeto E perguntei se eles conseguiam pensar em algum contexto em que o verbo 'passar' precisaria de 
complemento. Vários exemplos surgiram, como "me passa a caneta", "ele passou o rodo", "passar a roupa", "passar fila". Então, com os exemplos dos alunos, começamos a analisar o sentido de cada um, compreendendo a polissemia do verbo 'passar'.

\section{$\mathrm{RO} 2$}

E aí foi desafiador para mim porque eu já dei aula particular, mas as aulas particulares que eu dava, eu ia pelo tradicional porque o colégio era tradicional, então, não tinha dificuldade. Mas, quando eu me deparo... entrar numa escola, pegar um assunto, um conteúdo desse e trabalhar numa abordagem discursiva foi, de fato, desafiador. Aí eu aproveitei esse conhecimento prévio que eles tinham para trabalhar a relação entre semântica e sintaxe. Como a sintaxe pode mudar de acordo com a semântica... Então eu fui procurando tirinhas, fui trabalhando tirinhas que tivessem verbos que, a partir do momento que mudasse o contexto, que alterasse o sentido, também alterasse a sintaxe.

Este resultado pode ser explicado pelo que atesta Silva (2010) em um artigo a respeito das relações e tensões entre o ensino tradicional de gramática e a prática de análise linguística. Os dados da pesquisa da autora revelaram, entre outras coisas, que os conteúdos selecionados pelos professores observados funcionaram não só como objeto de ensino-aprendizagem, mas como definidores do quadro teórico-metodológico assumido; assim, conforme o conteúdo, o trabalho docente se aproximava de um modelo de ensino mais tradicional ou mais inovador, ou, ainda, determinou uma combinação de métodos e procedimentos. Diz a autora: "Conteúdos relativos a fatores de textualidade, por exemplo, parecem ser mais comumente abordados de forma reflexiva, próxima à proposta da $\mathrm{AL}$ [análise linguística]. Já os relativos à morfossintaxe só foram contemplados nos moldes tradicionais" (SILVA, 2010, p. 971).

\section{CRITÉRIO 4: PROCESSO DE DIDATIZAÇÃO DOS CONTEÚDOS}

Suassuna (2012, p. 21) afirma:

[...] O objetivo maior das aulas de português é formar o cidadão leitor e produtor de textos, entretanto, isso não será conseguido apenas com as práticas do ler e do escrever por si mesmas, mas com uma reflexão sistemática sobre essas práticas, reflexão que seja capaz de gerar teorias e explicações sobre o funcionamento dos textos e discursos e aplicações desses conhecimentos em situações novas.

Com base nisso, o critério 4 foi estabelecido para que pudéssemos perceber, de um lado, a correlação entre o projeto didático e os procedimentos metodológicos empregados e, de outro, o detalhamento do movimento indutivo de promoção da reflexão metalinguística e de geração de explicações sobre a língua pelos aprendizes.

Constatamos que, em PD1, PD3 e PD4, os gêneros textuais seriam utilizados para retirada de exemplos de frases e para que se pudesse efetuar identificação e classificação de palavras e regras gramaticais. Não é o texto, nesse caso, que demanda reflexões linguísticas, ele funciona apenas como uma forma material para: retirar exemplos e identificar e classificar diferentes modos verbais (PD1); servir como modelo para que os alunos empreguem regras de concordância verbal e nominal em ficha de exercícios (PD3); identificar elementos para a promoção de um debate sobre formação de palavras (PD4). Vejamos os trechos correspondentes:

PD1

Formar um círculo com as cadeiras / Pedir para que um primeiro aluno conte o começo de uma história da vida dele, depois o colega ao seu lado vai ter que completar com uma história que aconteceu com eles / 
Perguntar aos alunos em que tempo acontece a história contada por eles / Explicar os usos do verbo no passado e no futuro / Após isso, fazer uma explicação sobre tempos verbais / Será distribuída uma ficha de exercícios que os alunos deverão responder identificando e usando os tempos verbais

\section{PD3}

Ler junto com os alunos o conto "Apenas um conto de folia" / Questionar quais são os elementos do texto que constroem o sentido, levando os alunos a pensarem como fazem isso / Apresentar oralmente os conectores mostrando a sua importância como um emento da língua para estabelecer a coesão textual / Pedir aos alunos para voltar ao texto e procurar alguns desses elementos, escrevendo-os no quadro / Apresentar aos alunos os tipos de conjunções subordinativas e coordenativas, tentando classificar as que estão no quadro como sendo uma delas / Discutir sobre como esses elementos influenciam no entendimento do texto / Entregar aos alunos uma ficha com exercícios sobre elementos conectores / Retomar a leitura do artigo de opinião "A dor da separação e o prazer do recomeço" / Observar juntamente com os alunos a construção do texto: as palavras estão organizadas de forma que o texto tenha um sentido? Os pronomes, substantivos e verbos estão de acordo com o sujeito? / A partir dessas questões apresentar oralmente o conteúdo concordância nominal e verbal aos alunos, mostrando a sua importância como um elemento da língua para estabelecer a coerência textual / Primeiramente, estudar a concordância nominal apresentando suas regras e classificações, encontrando exemplos no artigo lido anteriormente / Em seguida, apresentar as classificações da concordância verbal, novamente usando o artigo anterior para encontrar tais exemplos / Refletir sobre como esses elementos influenciam no sentido do texto / Copiar no quadro uma síntese do conteúdo sobre concordância nominal e verbal / Entregar uma atividade impressa de modo que os alunos empreguem regras de concordância nominal e verbal, a partir do artigo de opinião "A dor da separação e o prazer do recomeço" / Corrigir a atividade coletivamente

\section{PD4}

Iniciarei a aula retomando o texto de Genilton Costa para destacar e analisar algumas palavras presentes no texto e junto com os alunos verificar como elas produzem efeitos de sentido. Partindo das observações dos alunos, será sistematizado, no quadro, como ocorre o processo de formação de palavras. Posteriormente às explicações, devolverei as produções textuais dos alunos e pedirei que em duplas troquem os textos e destaquem palavras que podem modificar o sentido dependendo da sua formação. Em seguida sistematizarei no quadro as palavras destacadas por cada aluno e discutirei a possibilidade de uso das palavras no texto.

No PD2, percebemos uma abordagem voltada para o funcionamento de elementos linguísticos em seu contexto de uso. As questões de predicação verbal foram associadas às questões semânticas, fazendo com que os alunos refletissem sobre o fato de que a predicação de um verbo pode mudar de acordo com a situação enunciativa. Assim, a reflexão sobre a língua contribuiu também para o desenvolvimento da prática de leitura:

\section{PD2}

A análise linguística será voltada para a análise da predicação do verbo de acordo com o contexto das tiras. Para isso, distribuirei cópias da tira de Orlandeli, depois farei junto com a turma uma análise. Iniciarei analisando a relação entre a linguagem verbal e a não verbal, sondando se eles conseguem identificar a intertextualidade existente na tira. E em seguida levantarei questionamentos sobre os vocábulos 'passarão' e 'passarinho', como o sentido deles muda conforme a função sintática e a predicação (no caso do verbo). Essas perguntas visam fazer com que eles vejam relação entre a predicação verbal e a semântica, levandoos a refletir sobre a dispensabilidade do complemento verbal no sentido do verbo 'passar' da tira analisada. Após a análise coletiva, pedirei que a turma se divida em quatro grupos e distribuirei tirinhas diferentes cujas falas também têm o verbo 'passar', a fim de que eles analisem e comparem. A análise deve ter como foco entender a relação entre a sintaxe e a semântica, uma vez que o sentido do verbo muda de acordo com o contexto, reflete em sua transitividade. Depois das análises, cada grupo deverá socializar com a turma o resultado da atividade, para que os pontos abordados pelos grupos possam ser discutidos, assim como acrescentar algum aspecto que não foi observado, potencializando a leitura da tira. 


\section{$=$ TRAMA $=$}

Nessa aula, os alunos irão pesquisar outras tiras levadas por mim, a fim de analisar a linguagem dos personagens, se é formal ou mais próxima da fala, observando os verbos e pronomes utilizados, expressões populares ou linguagem típica de uma região. Para isso, eles precisam observar quem enuncia, de onde enuncia, qual o contexto da enunciação e como isso exerce influência na linguagem, que nem sempre funciona conforme as regras da gramática normativa. As conclusões devem ser anotadas no caderno. Em seguida, os alunos deverão trocar de cadernos para avaliarem se concordam ou não com o registro feito.

O PD5, por sua vez, trouxe uma explicitação de como seria realizada a análise linguística a partir de um artigo de opinião. Consideramos pertinente o estudo das expressões modalizadoras proposto, pois é importante que os aprendizes saibam identificar os argumentos e as atitudes discursivas do autor do texto. Ademais, foi programada a realização de uma prática de escrita, mas não vimos a especificação de quais seriam os critérios discursivos, linguísticos e gramaticais para os quais os alunos deveriam atentar. O procedimento metodológico da segunda parte da análise linguística, associada ao gênero poema, apresentou a exploração da intergenericidade mas, ao mesmo tempo, continha uma lacuna em relação ao binômio formaconteúdo.

\section{PD5}

A partir da leitura dos artigos de opinião, discutir os aspectos estruturais do texto / Discutir a relação entre as expressões modalizadoras do texto por meio da continuação da leitura do artigo de Paulo Camargo, "O machismo vai à escola", extraído na revista "Planeta Sustentável" / Atividade de interpretação textual, dando enfoque aos elementos modalizadores e à influência destes na construção da coerência textual / Revisar e reescrever o artigo de opinião considerando critérios discursivos, linguísticos e gramaticais / Analisar o poema encontrando divergências entre forma e conteúdo / Reconhecer dentro do poema traços de outros gêneros / Entender o motivo do uso de estruturas de outros gêneros no poema / Refletir a respeito do efeito estético causado por essa estratégia poética.

Os achados indicam que a maioria dos licenciandos, de modo geral: não desenvolvem as aulas de acordo com o planejado no projeto didático; empregam mais a metodologia expositiva, por meio da qual fornecem informações aos alunos e realizam eles próprios as análises devidas; não detalham suficientemente as etapas de trabalho, na medida em que deixam de descrever os gestos didáticos realizados.

\section{CONSIDERAÇÕES FINAIS}

Como dito logo no início deste artigo, nosso objetivo foi identificar e analisar os modos como o licenciando de Letras-Português, no estágio de regência de aulas, atua para ensinar seus alunos a refletir sobre a língua, ou seja, como ele põe em prática a chamada análise linguística, no contexto de uma mudança paradigmática tanto da formação docente, quanto do ensino de língua portuguesa. Para tanto, analisamos dados provenientes de projetos, relatórios escritos e relatos orais produzidos por licenciandos que cursavam o estágio de regência de turma dos anos finais do ensino fundamental.

Realizamos nossa pesquisa acreditando que uma mudança em relação ao ensino de análise linguística é fundamental para a formação de sujeitos críticos e capazes de usar a língua(gem) e refletir sobre ela nos diversificados contextos de interação em que atuem, e acreditando, também, que mudar concepções e práticas de ensino de português sustentadas numa tradição secular não é algo que aconteça de modo rápido e automático.

Sobre o tema, Mendonça (2007, p. 108) afirma: 


\section{$=$ TRAMA $=$}

[...] essa mudança de perspectiva, de objetivos, de conteúdos a serem ensinados não é fácil para o professor. Alguns obstáculos surgem: sua própria formação enquanto aluno e posteriormente como professor, os anos de prática docente e a organização escolar, tudo isso reflete, na maioria dos casos, uma pedagogia tradicional de ensino de língua, que fragmenta as práticas linguísticas e ignora a produção de sentido como aspecto essencial. Porém, é possível e absolutamente necessário iniciar e ampliar as mudanças no ensino de AL e na sua avaliação.

Isso posto, constatamos em nosso estudo que os professores em formação têm conhecimento da concepção sociointeracionista da língua e procuram assumi-la em seu trabalho de regência de turma, utilizando, para isso, textos de diferentes gêneros. No entanto, a reflexão sobre a língua em sala de aula nem sempre pareceu surgir de processos interativos. Apesar de fazerem esforços para tratar a linguagem numa perspectiva textual-discursiva, os estagiários ainda mantêm algumas práticas tradicionais, como exposição de conteúdos e atividades de identificação, classificação e nomeação de elementos gramaticais (sobretudo quando se trata de assuntos impostos pela escola).

Outra questão é que, embora tenham indicado instrumentos e critérios de avaliação da aprendizagem de conhecimentos linguísticos nos planejamentos, os estagiários não deram indicações, nem nos relatos orais, nem nos relatórios escritos, de como essa avaliação foi realizada. Também não foram mostrados os desempenhos dos alunos, nem as estratégias utilizadas para sanar dificuldades e problemas eventualmente encontrados.

Os procedimentos didáticos relativos à prática de análise linguística não foram bem explicitados e, pelas descrições realizadas, vimos que predominou uma abordagem expositiva e dedutiva. Nesse sentido, julgamos necessário um tratamento específico e mais aprofundado dos modos de ensinar análise linguística ao longo do curso de formação inicial, notadamente nos componentes curriculares que têm relação mais direta com a didática da língua portuguesa.

Por fim, entendemos que o estágio de regência de turma deve ser alvo de novos estudos e pesquisas, mais especificamente a respeito da didatização dos saberes linguísticos, a qual ainda representa um grande desafio no campo da didática da língua portuguesa.

\section{REFERÊNCIAS}

ALMEIDA FILHO, J. C. Crise, transições e mudança no currículo de formação de professores de línguas. In: FORTKAMP, M. B. M.; TOMITCH, L. M.B. (org.). Aspectos da linguística aplicada: estudos em homenagem ao professor Hilário Inácio Bohn. Florianópolis: Insular, 2000. p. 33-47.

AZEVEDO, T. M. Ensinar gêneros? Desenredo, Passo Fundo, RS, v. 10, n. 1, p. 92-103 - jan./jun. 2014.

AZEVEDO, T. M. Transposição didática de gêneros discursivos: algumas reflexões. Desenredo. Passo Fundo, RS, v. 6, n. 2, p. 198-214 - jul./dez. 2010.

BARBOSA, J. Análise e reflexão sobre a língua e as linguagens: ferramentas para os letramentos. In:

RANGEL, E. O.; ROJO, R. H. R. (org.) Língua Portuguesa no Ensino Fundamental. Coleção Explorando o Ensino. vol. 19. Brasília: MEC/SEB, 2010, p. 155-182.

CALLIAN, G. R.; BOTELHO, L. S. A análise linguística e o ensino de língua portuguesa: em busca do desenvolvimento da competência discursiva. Educação em Destaque. Juiz de Fora, MG, v. 5, n. 1, p. 1-21, 2014.

DICKEL, A. Ensino de gramática: das polêmicas às proposições. In: SEMINÁRIO NACIONAL SOBRE LINGUAGENS E ENSINO, 7, 2012, Pelotas. Anais... Pelotas: UCPel, 2012.

DUTRA. C. M. D.; LOULA, L. D. Incompreensão e desalinhamento teórico-metodológico como possíveis entraves à prática de análise linguística em sala de aula. Domínios de Lingu@gem, Uberlândia, MG, vol. 11, n. 3, p. 526-547, jul./set. 2017.

EMILIO, A. Gramática, deve-se ou não se deve ensinar? Línguas \& Letras. Cascavel, PR, v. 9. n. 16, p. 2735. 2007.

GERALDI, J. W. Concepções de linguagem e ensino de português. In: GERALDI, J. W. (org.). O texto na sala de aula. São Paulo: Ática, 1997[1984], p. 39-46.

GERALDI, J. W. Unidades básicas do ensino de português. In: GERALDI, J. W. (org.). O texto na sala de aula: leitura e produção. Cascavel: Assoeste, 1984, p. 49-69. 
LARROSA, Jorge. Algunas notas sobre la experiencia y sus lenguajes. In: BARBOSA, R. L. L. (org.).

Trajetórias e perspectivas da formação de educadores. São Paulo: Ed. Unesp, 2004. p.19-34.

LOMBARDI, R. F. e ARBOLEA, T. A. Formando professores pesquisadores do ensino de língua materna. In: CONGRESSO LATINO-AMERICANO SOBRE FORMAÇÃO DE PROFESSORES DE LÍNGUA. 1, Florianópolis, Anais... 2006, p. 614-619.

MENDONÇA, M. Análise linguística: por que e como avaliar. In: Marcuschi, B. SUASSUNA, L. (org.).

Avaliação em língua portuguesa: contribuições para a prática pedagógica. Belo Horizonte: Autêntica, 2007, p. 95-110.

NÓBREGA, J. J.; SUASSUNA, L. Aula de gramática ou de análise linguística? Investigando objetos de estudo e objetivos norteadores. Linguagens, Educação e Sociedade. Teresina, PI, n. 31, p. 246-269, jul. 2014.

OLIVEIRA, M. B. F. Revisitando a formação de professores de língua materna: teoria, prática e construção de identidades. Linguagem em (Dis)curso. Tubarão, SC, v. 6, n. 1, p. 101-117, jan./abr. 2006.

PETRONI, M. R.; JUSTINO, A. R.; MELO, E. S. O. Ainda sobre a formação do professor de língua portuguesa no Brasil. Interacções, Santarém, PT, n. 19, p. 28-37, 2011.

PIMENTA, S. G.; LIMA, M. S. L. Estágio e docência: diferentes concepções. Poiésis. Tubarão, SC, vol. 3, números 3 e 4, p. 5-24, 2006.

RAUBER, A. L. A formação do professor de Língua Portuguesa: o diálogo entre teoria e prática. In:

MAGALHÃES, J. S.; TRAVAGLIA, L. C. (org.). Múltiplas perspectivas em linguística. Uberlândia/MG: EDUFU, 2008, v. 01, p. 346-356.

REINALDO, M. A. G. M. O conceito de análise linguística como eixo de ensino de língua portuguesa no Brasil. Estudos Linguísticos, n. 8. Edições Colibri/CLUNL, Lisboa, p. 229-241, 2012.

REMENCHE, M. L. R.; ROHLING, N. Análise linguística e formação de professores: um discurso sobre a dicotomia teoria e prática. In: SIMPÓSIO MUNDIAL DE ESTUDOS DE LíNGUA PORTUGUESA. SIMELP. 5 , 2017. Salento. Atas... Salento: Università del Salento, 2017.

SILVA, N. I. Ensino tradicional de gramática ou prática de análise linguística: uma questão de (con)tradição nas aulas de português. Revista Brasileira de Linguística Aplicada. Belo Horizonte, MG, v. 10, n. 4, p. 949973, 2010.

SILVA, W. R.; FAJARDO-TURBIN, A. E. F. Relatório de estágio supervisionado como registro da reflexão pela escrita na profissionalização do professor. Polifonia, Cuiabá, MT, v. 18, n. 23, p. 103-128, jan./jun., 2011. SIQUEIRA, R. A. R.; MESSIAS, R. A. L. Reflexão e ações na formação e atuação do professor de língua portuguesa: o diálogo como condição de autoria na prática educativa. In: Linguagem \& Ensino, Pelotas, RS, v.11, n.2, p.377-392, jul./dez. 2008.

SUASSUNA, L. Ensino de análise linguística: situando a discussão. In: SILVA, A.; PESSOA, A. C.; LIMA, A. (org.). Ensino de gramática: reflexões sobre a língua portuguesa na escola. Belo Horizonte, MG: Autêntica Editora, 2012, p. 11-28.

TARDIF, M.; LESSARD, C.; LAHAYE, L. Os professores face ao saber: esboço de uma problemática do saber docente. Teoria e Educação, Porto Alegre, RS, v. 04, p. 215-233, 1991.

VIEIRA, S. R. Prática de análise linguística sem ensino de gramática? Reflexões e propostas. In: ATAÍDE, C. et al. (org.). GELNE 40 anos. Experiências teóricas e práticas nas pesquisas em Linguística e Literatura. Paulo: Blucher, 2017, p. 299-318. 